\title{
Effect of taurine and bile acid supplementation and their interaction on performance, serum components, ileal viscosity and carcass characteristics of broiler chickens
}

\author{
M.H. Alzawqari ${ }^{1}$, H.H. Al-Baadani ${ }^{2}$, I.B. Alhidary ${ }^{2,}$ A.N. Al-Owaimer ${ }^{2}$ \& A.M. Abudabos ${ }^{2 \#}$ \\ ${ }^{1}$ Department of Animal Production, Faculty of Agriculture and Veterinary Medicine, Ibb University, Ibb, Yemen \\ ${ }^{2}$ Department of Animal Production, College of Food and Agriculture Sciences, King Saud University, Saudi Arabia
}

(Received 29 March 2016; Accepted 29 November 2016; First published online 3 December 2016)

\author{
Copyright resides with the authors in terms of the Creative Commons Attribution 2.5 South African License. \\ See: http://creativecommons.org/licenses/by/2.5/za \\ Condition of use: The user may copy, distribute, transmit and adapt the work, but must recognize the authors and the South African \\ Journal of Animal Science.
}

\begin{abstract}
A $3 \times 3$ factorial experiment (4 pens/treatment, 10 birds/pen) was conducted with 3 levels of supplemental taurine (Tau) $(0.0,0.25$ and $0.50 \%)$ and 3 levels of dissected bile acid (DBA): $0.0,0.25$ and $0.50 \%$ of the diet were arranged in a completely randomized design. Isocaloric and isonitrogenous starter and grower diets were fed ad libitum to chickens from $7-21$ and $22-42 \mathrm{~d}$, respectively. The measured parameters were body weight gain (BWG), feed intake (FI), feed conversion ratio (FCR), fat digestibility, serum cholesterol (Chol), triglyceride (TG), high-density lipoprotein (HDL), and low-density lipoprotein (HDL). The supplementation of Tau had no effect on FI, BWG and FCR for all periods. Moreover, BWG and FCR were a function of the DBA level in the diet for the finisher and the cumulative periods; birds which received the highest level of DBA (0.50\%) had the highest BWG and the best FCR as compared to 0.0 and $0.25 \%$. Fat digestibility was significantly improved by Tau and DBA supplementation. DBA and Tau supplementation had increased serum components at 21 and $42 \mathrm{~d}$ of age. The supplementation of Tau or DBA in the diets did not affect carcass parameters at $42 \mathrm{~d}$ of age. However, a linear reduction on the small intestinal weight was observed as a result of DBA supplementation. Supplementation of the diets with Tau significantly increased bursa weights. The results of this study indicated that Tau had limited impact on performance, while the supplementation of DBA at $0.50 \%$ had the best improvements in performance and blood characteristics and this could be explained in part by its positive effect on fat digestibility.
\end{abstract}

Keywords: Broilers, blood parameters, desiccated bile acid, performance, taurine

\#Corresponding author: alabudabos@gmail.com

\section{Introduction}

Taurine is an amino acid that is synthesized from methionine and is one of the end products of sulfur metabolism (Tufft \& Jensen, 1992). Taurine has many functions in the body such as neuromodulator, antioxidation, immunomodulator, and plays an important role in cardiac and brain functions. Taurine exists in the small intestine at high concentrations where it plays a significant role in the intestinal functions such as in bile acid conjugation such as cholic or chenodeoxycholic acid in the liver (Huang et al., 2014a). Bile acids are synthesized from cholesterol and conjugated to either glycine or taurine in the pericentral hepatocytes of the liver, stored and concentrated in the gallbladder, and released into the duodenum where they play a significant role in enhancing fat digestion thorough bile salt micellar solubilization of fats and subsequently increasing absorption (Begley et al., 2005; Reshetnyak, 2013).

In poultry nutrition, the value of the various fat sources depends on fatty acids profile, energy contents, digestibility and absorption. Digestion of fat is influenced by many factors, such as bile secretion and dietary fat sources (Preston et al., 2001; Abudabos, 2014). On the other hand, secretion of bile salts, which is required for normal emulsification and micelle formation in the intestine, is influenced by quantity and quality of dietary fat and other emulsifiers. Several studies have shown that low concentration of bile salt secretion and activity of pancreatic lipase in young chicks appears to be the first limiting factors for lipid digestion in the first three weeks of post hatch. Therefore, several attempts have been made to improve fat digestion in poultry, especially at young ages. For example, Azman et al. (2005) reported that supplementary cholic acid to a diet containing mixture of palmitic and oleic acids resulted in better performance of broilers as a result of metabolizable energy (ME) improvement. Maisonnier et al. (2003) reported that the addition of bile 
salts to broiler diets did not affect the small intestinal supernatant viscosity, but an improvement in weight gain was observed. Parsaie et al. (2007) demonstrated that the supplementation of bile acid to wheat-based diets improved body weight gain and feed consumption of broiler chickens. Reinhart et al. (1988) also reported that the performance of weaned pigs increased significantly as inclusion of bile salt in the diet was increased. In our previous studies, it was shown that dietary desiccated ox bile can be used as a natural nonnutrient additive to improve tallow digestibility in broilers and performance in general through stimulation of morphological maturation of gastrointestinal tract (Alzawqari et al., 2010; Alzawqari et al., 2011).

The present study therefore aims at investigating the effects of various concentrations of Taurine (Tau) and desiccated bile acid (DBA) and their interactions on performance, fat digestibility, blood chemistry, ileal digesta viscosity, and carcass characteristics of male broiler chickens fed diets supplemented with saturated fats.

\title{
Materials and Methods
}

The DBA product which was used at this trial was prepared from fresh bile acid which was collected from the gall bladder of oxen at a local slaughterhouse. Thereafter, homogenates of bile acids were filtered through a coarse nylon mesh, concentrated and dried under a high vacuum at low temperature, and immediately stored at $-20^{\circ} \mathrm{C}$ to prevent decomposition (Irvin et al., 1939; Coleman et al., 1979). Colour and some typical analysis characteristics of DBA after processing are shown in Table 1. DBA was checked to be free from contamination such as $E$. coli and Salmonella spp.

Table 1 Typical analysis characteristics of collected desiccated bile acid (DBA)

\author{
Color of the powder \\ Color in solution \\ Solubility (\%) \\ $\mathrm{pH}$ \\ Total ash (\%) \\ Water (\%) \\ DBA \%
}

\author{
brownish to yellow \\ yellow-beige \\ 100.0 \\ $5.5-7.5$ \\ 15.0 \\ 5.0 \\ 80.0
}

A total of 360 day-old chicks (Ross 308 ) were randomly divided into 36 floor pens and received 9 treatments (4 replicates per treatment) under a completely randomized design. A factorial arrangement of 3 levels of taurine (Tau) $(0.0$ (control), 0.25 and $0.50 \%$ ) and 3 levels of desiccated bile acid (DBA) $(0.0$ (control), 0.25 , and $0.50 \%$ ) were used in the trial. The experimental diets were given to chickens for starter (7 - $21 \mathrm{~d}$ ) and grower (22 - $42 \mathrm{~d}$ ) periods in mashed form (Table 2). Feed and water were provided ad libitum and a $23 \mathrm{~h}$ light schedule was maintained throughout.

Body weight gain (BWG) and feed intake (FI) of each pen was measured at the end of each period and feed conversion ratio (FCR) was calculated for the periods $7-21$ and $22-42 \mathrm{~d}$ of age and for the cumulative period ( $7-42 \mathrm{~d}$ ). Mortality was checked daily and weights of dead birds were used to adjust FCR (mortality-corrected FCR). The chromic oxide marker method of Scott et al. (1976) was used to measure fat digestibility. Chromic oxide was supplemented to the diets at a rate of $3 \mathrm{~g} / \mathrm{kg}$ and digestibility was determined at 21 and $42 \mathrm{~d}$ of age. Chromic oxide-marked feeds were fed to four pens of chickens per treatment for an adaptation period and then excreta were collected for 3 days (days 19 - 21 and 40 - 42). Contaminants such as feathers and scales were carefully removed and then excreta were stored at $-20{ }^{\circ} \mathrm{C}$ for further analyses. Fat contents (ether extract) of the diet and excreta samples were determined using Soxhlet extraction (Soxtec System HT 1043 Extraction unit, Foss Corporation, Sweden) according to the standard procedures (AOAC, 2006). Chromic oxide was determined using the method of Fenton \& Fenton (1979). The following equation was used for calculation of percent retention:

$$
\% \text { fat digestibility }=100-\left[\left(\text { Diet } \mathrm{Cr}_{2} \mathrm{O}_{3} / \text { Fecal } \mathrm{Cr}_{2} \mathrm{O}_{3}\right) \times(\text { Fecal fat/diet fat })\right] \times 100 \text { (Scott et al., 1976). }
$$

On days 21 and 42, 4 birds per treatment were randomly selected and blood samples were withdrawn from the wing vein; serum was obtained and stored at $-20^{\circ} \mathrm{C}$. At the time of analysis, serum samples were thawed and serum cholesterol (Chol), triglyceride (TG), high density lipoprotein (HDL) and low density lipoprotein (LDL) were determined using an autoanalyzer (Autolab, BT 3500, Autoanalyzaer Medical System, Italy). 
Table 2 Diet composition and calculated nutrient content

\begin{tabular}{lcc}
\hline Ingredient (\%) & Starter diet $(7-21 \mathrm{~d})$ & Grower diet $(22-42 \mathrm{~d})$ \\
\hline Yellow maize & 49.27 & 53.06 \\
Soybean meal $(44 \% \mathrm{CP})$ & 37.63 & 28.45 \\
Wheat bran & 4.30 & 10.32 \\
Dicalcium phosphate & 1.47 & 1.01 \\
Limestone & 1.42 & 1.31 \\
Salt & 0.43 & 0.30 \\
Tallow & 5.00 & 5.00 \\
DL-Methionine & 0.15 & 0.05 \\
Vit. \& Min. premix ${ }^{1}$ & 0.50 & 0.50 \\
Total & 100.00 & 100.00 \\
\hline Calculated nutrient content $(\%$, unless otherwise stated) & 12.35 \\
ME, MJ/kg & 12.35 & 18.44 \\
Crude protein & 21.20 & 7.57 \\
Crude fat & 7.32 & 4.35 \\
Crude fiber & 4.25 & 0.83 \\
Calcium & 0.92 & 0.32 \\
Available phosphorus & 0.42 & 0.14 \\
Sodium & 0.18 & 1.21 \\
Arginine & 1.42 & 0.97 \\
Lysine & 1.17 & 0.66 \\
Methionine + cysteine & 0.83 & 0.30 \\
Tryptophan & 0.32 & \\
& &
\end{tabular}

At 21 and $42 \mathrm{~d}$ of age, 4 birds per treatment were randomly selected, weighed and euthanized by cervical dislocation. The ileum (midway between Meckel's diverticulum and the ileo-cecal junction) was dissected aseptically and the digesta contents were collected and pooled by replicate as described by (Lazaro et al., 2004). The digesta was homogenized and 2 tubes were filled (1.5 g of sample) and centrifuged $(12,000 \times \mathrm{g}$ for $3 \mathrm{~min}$ ). The viscosity (in centipoises, $\mathrm{cP}$ ) of a $0.5 \mathrm{ml}$ aliquot obtained from the supernatant solution was determined at 21 and $42 \mathrm{~d}$ of age with a Brookfield digital viscometer (model DV-II, Brookfield Engineering Laboratories Inc., Stoughton, MA 02072, USA) at $37^{\circ} \mathrm{C}$.

At $42 \mathrm{~d}$ of age, one bird per replicate were randomly chosen, based on the average weight of the group and euthanized by cervical dislocation. Feather, heads and shanks were removed, and the remaining carcasses were dissected. Carcass yield was calculated by dividing the eviscerated weight by live weight. Empty small intestine, abdominal fat, bursa, spleen, and liver were removed, weighed, and the percentage of each part was calculated based on live body weight. Additionally, the length of the small intestinal was measured.

All data were analyzed using the General Linear Model procedure of the Statistical Analysis System (SAS, 2004) as a $3 \times 3$ factorial arrangement of treatments that included dietary supplementation of Tau (3 levels) and DBA ( 3 levels), and their respective interactions. Tukey's test was applied to compare the treatment means when the treatment effect was significant at a $P<0.05$ statistical level.

\section{Results and Discussion}

The effects of Tau, DBA supplementation and their interaction on BWG, FI and FCR are given in Table 3. The supplementation of Tau to broiler diets did not affect FI, BWG and FCR for the periods $7-21,22-42$ 
and 7 - 42 days of age. Previous studies have shown either a momentary improvement or no improvement in performance as a result of Tau supplementation to broiler's diet. In agreement with our results, Blair et al. (1991) found that Tau supplementation of $0.025,0.05$ or $0.10 \%$ to the diet had no effect on growth of male broiler chicks $(P>0.05)$. The same result was found in a study of Tufft \& Jensen (1992) who reported no differences in growth performance of broiler chickens or turkeys fed Tau. Recently, Huang et al. (2014b) reported that Tau supplementation at a rate of $0,0.0125,0.05,0.20$ or $0.80 \%$ Tau from 1 to $42 \mathrm{~d}$ of age had no positive effects on performance of broilers. However, Divakaran (2006) found that $0.1 \%$ Tau added to a soybean meal and glucose diet resulted in a temporary improvement in growth only in the early weeks of life. Campbell \& Classen (1989) reported a decrease in feed to gain ratio in male broiler chickens that received Tau from 3 to 6 weeks, but no effect during 0 to 3 weeks they also reported no effect of Tau on body weight at 3 or 6 weeks of age.

In the present study, the supplementation of DBA to broiler diets had no significant effects on FI, BWG and FCR during the starter period (7 - 21d). A significant interaction between Tau and DBA was observed for the FI of broilers during $22-42 \mathrm{~d}$ of age. However for the grower period (22- $42 \mathrm{~d}$ ) and the cumulative period $(7-42 \mathrm{~d})$, birds which received 0.25 and $0.50 \%$ DBA had higher $\mathrm{FI}$ than those which received $0.0 \%(P$ $<0.001$ ). Moreover, for the finisher and the cumulative periods, BWG and FCR were a function of the DBA level in the diet. Birds which received the highest level of DBA $(0.50 \%)$ had the highest BWG and the best FCR as compared to 0.0 and $0.25 \%(P<0.01)$, while birds which received $0.25 \%$ DBA had better BWG and FCR than those which received $0.0 \%(P<0.01)$. Similarly, Parsaie et al. (2007) reported a significant increase in FI and BWG of broilers fed a diet supplemented with bile acid when compared to the control group. Maisonnier et al. (2003) reported that the addition of bile salts to broiler diets increased weight gain. The significant improvement observed in BWG and FCR of DBA supplemented diets during the finisher and cumulative periods could be related to higher fat digestion as a result of DBA supplementation which was observed in this trial. The interaction between DBA and Tau was not significant for BWG and FCR during all periods which could indicate the lack of synergism between DBA and Tau.

Table 3 Effect of taurine (Tau) and dissected bile acid (DBA) supplementation on performance of male broiler chickens during 7 to $42 \mathrm{~d}$ of age

\begin{tabular}{|c|c|c|c|c|c|c|c|c|c|}
\hline \multirow{2}{*}{ Main effects } & \multicolumn{3}{|c|}{ Feed intake (g/b/d) } & \multicolumn{3}{|c|}{ Body weight gain (g/b/d) } & \multicolumn{3}{|c|}{ Feed conversion ratio (g:g) } \\
\hline & $7-21$ & $22-42$ & $7-42$ & $7-21$ & $22-42$ & $7-42$ & $7-21$ & $22-42$ & $7-42$ \\
\hline \multicolumn{10}{|l|}{ Tau (\%) } \\
\hline 0.00 & 51.0 & 118.7 & 89.9 & 30.0 & 49.0 & 38.7 & 1.71 & 2.53 & 2.39 \\
\hline 0.25 & 52.1 & 120.7 & 91.5 & 29.2 & 50.3 & 39.5 & 1.79 & 2.45 & 2.38 \\
\hline 0.50 & 49.4 & 119.6 & 89.7 & 28.3 & 51.4 & 40.3 & 1.76 & 2.39 & 2.28 \\
\hline \multicolumn{10}{|l|}{ DBA (\%) } \\
\hline 0.00 & 51.2 & $108.6^{b}$ & $83.9^{\mathrm{b}}$ & 28.9 & $38.0^{\circ}$ & $33.0^{\mathrm{C}}$ & 1.78 & $2.88^{\mathrm{a}}$ & $2.61^{a}$ \\
\hline 0.25 & 51.0 & $124.1^{\mathrm{a}}$ & $93.0^{\mathrm{a}}$ & 29.3 & $53.6^{b}$ & $41.2^{b}$ & 1.75 & $2.33^{b}$ & $2.30^{b}$ \\
\hline 0.50 & 50.4 & $124.8^{\mathrm{a}}$ & $94.2^{\mathrm{a}}$ & 29.3 & $59.0^{\mathrm{a}}$ & $44.3^{\mathrm{a}}$ & 1.72 & $2.16^{\mathrm{C}}$ & $2.15^{b}$ \\
\hline SEM & 1.85 & 2.39 & 1.97 & 1.24 & 2.22 & 1.27 & 0.06 & 0.10 & 0.13 \\
\hline \multicolumn{4}{|c|}{ Source of variance } & \multicolumn{5}{|c|}{$P$-value } & \\
\hline Tau (\%) & 0.217 & 0.596 & 0.485 & 0.293 & 0.408 & 0.328 & 0.262 & 0.286 & 0.529 \\
\hline DBA (\%) & 0.862 & 0.001 & 0.001 & 0.882 & 0.001 & 0.001 & 0.486 & 0.001 & 0.006 \\
\hline Tau $\times$ DBA & 0.753 & 0.023 & 0.093 & 0.474 & 0.072 & 0.317 & 0.795 & 0.229 & 0.984 \\
\hline
\end{tabular}

The effect of different levels of Tau and DBA on fat digestibility is presented in Table 4. Fat digestibility was significantly affected by Tau and DBA supplementation and their interaction $(P<0.05)$. At $22 \mathrm{~d}$, birds which received 0.25 or $0.50 \%$ Tau had higher fat digestibility those which received $0.0 \%(P<0.01)$. At $42 \mathrm{~d}$, birds which received $0.5 \%$ Tau had higher fat digestibility than those which had $0.0 \%$, while those that received $0.25 \%$ were intermediate $(P<0.05)$. 
Table 4 Effect of taurine (Tau) and dissected bile acid (DBA) levels on fat digestibility (\%) of male broiler chickens at 21 and $42 \mathrm{~d}$ of age

\begin{tabular}{|c|c|c|c|}
\hline \multirow{2}{*}{\multicolumn{2}{|c|}{ Main effects }} & \multicolumn{2}{|c|}{ Period (days) } \\
\hline & & $21 d$ & $42 \mathrm{~d}$ \\
\hline \multicolumn{4}{|c|}{$\operatorname{Tau}(\%)$} \\
\hline \multicolumn{2}{|l|}{0.00} & $64.35^{\mathrm{b}}$ & $71.31^{b}$ \\
\hline \multicolumn{2}{|l|}{0.25} & $69.02^{\mathrm{a}}$ & $72.54^{\mathrm{ab}}$ \\
\hline \multicolumn{2}{|l|}{0.50} & $70.68^{a}$ & $74.42^{\mathrm{a}}$ \\
\hline \multicolumn{4}{|c|}{ DBA (\%) } \\
\hline \multicolumn{2}{|c|}{0.00} & $55.78^{c}$ & $59.26^{c}$ \\
\hline \multicolumn{2}{|l|}{0.25} & $70.22^{b}$ & $74.80^{b}$ \\
\hline \multicolumn{2}{|l|}{0.50} & $75.05^{\mathrm{a}}$ & $84.22^{\mathrm{a}}$ \\
\hline \multicolumn{2}{|l|}{ SEM } & 1.63 & 1.32 \\
\hline \multicolumn{4}{|c|}{ Interaction effects } \\
\hline \multicolumn{4}{|c|}{ Tau $\times$ DBA } \\
\hline \multicolumn{4}{|c|}{$0.00 \quad 0.00$} \\
\hline 0.00 & 0.25 & $76.95^{\mathrm{ab}}$ & $77.89^{b}$ \\
\hline & 0.50 & $70.64^{\mathrm{bcd}}$ & $78.19^{b}$ \\
\hline & 0.00 & $58.08^{e}$ & $58.09^{c}$ \\
\hline 0.25 & 0.25 & $74.00^{\mathrm{abc}}$ & $74.09^{b}$ \\
\hline & 0.50 & $74.96^{\mathrm{abc}}$ & $85.44^{\mathrm{a}}$ \\
\hline & 0.00 & $63.79^{\mathrm{de}}$ & $61.84^{\mathrm{C}}$ \\
\hline & 0.25 & $68.71^{\mathrm{cd}}$ & $72.041^{\mathrm{ab}}$ \\
\hline & 0.50 & $79.54^{\mathrm{a}}$ & $89.03^{a}$ \\
\hline \multicolumn{2}{|c|}{ Source of variance } & & \\
\hline \multicolumn{2}{|c|}{ Tau (\%) } & 0.005 & 0.031 \\
\hline \multicolumn{2}{|c|}{ DBA (\%) } & 0.001 & 0.001 \\
\hline \multicolumn{2}{|c|}{ Tau $\times$ DBA } & 0.001 & 0.002 \\
\hline
\end{tabular}

On the other hand, increased DBA level in the diet caused increased fat digestibility at 21 and 42 days in a linear way $(P<0.001)$. The interaction between DBA and Tau was significant for fat digestibility at 21 and $42 \mathrm{~d}$. At $21 \mathrm{~d}$, the highest digestibility was achieved when $0.5 \%$ Tau and $0.5 \%$ DBA were used but it was not different when 0.25 and $0.50 \%$, or 0.25 and $0.25 \%$, or 0.0 and $0.25 \%$ of Tau and DBA were used, respectively. At $42 \mathrm{~d}$, the highest digestibility was achieved when $0.50 \%$ Tau and $0.50 \%$ DBA were used but it was not different when 0.50 and $0.25 \%$, or 0.25 and $0.5 \%$ of Tau and DBA were used, respectively. The fat digestibilities were inconsistent across the levels of Tau and DBA that were used and this inconsistency created the significant interaction. Similar responses were obtained by Zeng et al. (2011), who reported that an addition of $0.15 \%$ Tau increased crude fat digestibility. Previous studies showed that the major effect of Tau seems to be on the improvement of absorption of saturated fatty acids (Noy \& Sklan, 2001). According to Haslewood (1967), Tau plays a well-recognized role in fat digestion when it conjugates with bile acids, such as cholic acid or chenodeoxycholic acid, in the liver. It has also been reported that taurocholate is a more efficient bile acid in fat absorption, because taurine-conjugated bile acids are better emulsifiers of fat than glycine-conjugated bile acids (Chesney et al., 1998).

The supplementation of bile salt to broiler diets improved fat digestibility $(P<0.001)$. It has been proposed that the improvement in fat digestibility by addition of bile salt may be due to deficient bile salt secretion by the animal or renewal of the active catabolism of bile salts by the intestinal microflora (Adrizal et al., 2002; Maisonnier et al., 2003). Other researchers proposed another advantage of dietary bile salt in 
enhancing the digestibility of saturated fatty acids with long chains (Gomez \& Polin, 1976; Kocsar et al., 1969). Generally, the improvement of digestibility coefficients by supplementing emulsifier to the diet occurs because non-fat nutrients become less protected by fat droplets and henceforth more available for digestive enzymes. The improvement in performance reported in this trial could be explained by the fact that the detergent property of bile converses potent antimicrobial activity and defense mechanism of the microorganism against bacterial endotoxins (Begley et al., 2005). Young et al. (1963) validated that addition of antibiotics to chick's diets appeared to increase their fat utilization by reducing intestinal microbial populations and thus reducing their rate of bile salt catabolism.

Table 5 shows the serum Chol, HDL, LDL and TG contents of broilers fed diets containing various levels of Tau and DBA. At $21 \mathrm{~d}$ of age, Chol, TG and LDL were affected by Tau level in the diet $(P<0.05)$. Birds that received 0.25 and $0.50 \%$ Tau had higher Chol concentration, those which received $0.25 \%$ Tau had higher TG concentration while those received 0.5\% Tau had higher LDL concentration than those which received $0 \%$ Tau. There were no significant differences in the (HDL) among birds fed different levels of Tau at $21 \mathrm{~d}$. At $42 \mathrm{~d}$ of age, only Chol and HDL concentration were affected by Tau levels, birds which received 0.25 or $0.50 \%$ Tau had higher Chol and HDL concentrations than $0.0 \%$ Tau. Several earlier studies showed that taurine supplementation had clear effect on reducing serum and liver cholesterol, triglycerides and atherosclerotic lipid accumulation (Matsushima et al., 2003; Militante \& Lombardini, 2004). These results are consistent with the findings of Shim (2010) who observed that Tau supplementation improved serum total cholesterol and triglyceride concentration of laying hens fed high fat diet. A recent study showed that $0.20 \%$ taurine supplementation increased the content of serum HDL, serum lipoprotein lipase and liver hepatic lipase activity (Zeng et al., 2011)

Table 5 Effect of supplemental taurine (Tau) and dissected bile acid (DBA) levels on serum components $(\mathrm{mg} / \mathrm{dl})$ of male broiler chickens at 21 and $42 \mathrm{~d}$ of age

\begin{tabular}{|c|c|c|c|c|c|c|c|c|}
\hline \multirow{3}{*}{ Main effects } & \multicolumn{8}{|c|}{ Period (days) } \\
\hline & \multicolumn{4}{|c|}{21} & \multicolumn{4}{|c|}{42} \\
\hline & Chol & TG & $\mathrm{HDL}$ & LDL & Chol & TG & $\mathrm{HDL}$ & LDL \\
\hline \multicolumn{9}{|l|}{ Tau (\%) } \\
\hline 0.00 & $116.00^{b}$ & $72.44^{\mathrm{b}}$ & 68.67 & $37.44^{\mathrm{b}}$ & $83.00^{b}$ & 35.67 & $54.11^{\mathrm{b}}$ & 21.44 \\
\hline 0.25 & $140.44^{a}$ & $102.33^{a}$ & 76.33 & $44.44^{\mathrm{ab}}$ & $111.56^{a}$ & 49.44 & $75.33^{a}$ & 23.67 \\
\hline 0.50 & $132.22^{\mathrm{a}}$ & $86.00^{a b}$ & 75.89 & $45.33^{a}$ & $102.22^{a}$ & 46.33 & $72.44^{\mathrm{a}}$ & 25.89 \\
\hline \multicolumn{9}{|l|}{ DBA (\%) } \\
\hline 0.00 & $106.33^{c}$ & $75.22^{b}$ & $57.67^{\mathrm{b}}$ & $32.00^{b}$ & $68.22^{c}$ & $35.67^{b}$ & $48.44^{\mathrm{c}}$ & $19.44^{\mathrm{b}}$ \\
\hline 0.25 & $130.22^{b}$ & $84.89^{\mathrm{ab}}$ & $67.76^{\mathrm{a}}$ & $44.11^{a}$ & $105.89^{b}$ & $43.56^{\mathrm{ab}}$ & $66.56^{\mathrm{b}}$ & $25.44^{\mathrm{a}}$ \\
\hline 0.50 & $152.11^{\mathrm{a}}$ & $100.67^{\mathrm{a}}$ & $86.44^{\mathrm{a}}$ & $51.11^{\mathrm{a}}$ & $122.67^{\mathrm{a}}$ & $52.22^{\mathrm{a}}$ & $86.89^{a}$ & $26.11^{\mathrm{a}}$ \\
\hline SEM & 6.81 & 11.54 & 4.47 & 3.75 & 5.00 & 7.91 & 7.77 & 2.45 \\
\hline Source of variance & \multicolumn{8}{|c|}{$P$-value } \\
\hline Tau (\%) & 0.001 & 0.018 & 0.106 & 0.037 & 0.001 & 0.110 & 0.007 & 0.113 \\
\hline DBA (\%) & 0.001 & 0.045 & 0.001 & 0.001 & 0.001 & 0.061 & 0.001 & 0.007 \\
\hline Tau $\times$ DBA & 0.073 & 0.119 & 0.100 & 0.138 & 0.243 & 0.511 & 0.619 & 0.069 \\
\hline
\end{tabular}

abc Means with different superscripts within the same column are significantly different $(P<0.05)$.

$\mathrm{Chol}=$ cholesterol, $\mathrm{TG}=$ triglyceride, $\mathrm{HDL}=$ high-density lipoprotein, and $\mathrm{LDL}=$ low-density lipoprotein .

DBA supplementation of the diets had significantly increased serum components of Chol, TG, HDL and LDL concentrations at 21 and $42 \mathrm{~d}$ of age. These parameters were the highest for birds that received $0.50 \%$ DBA as compared to $0.0 \%$. All parameters were similar between 0.25 and $0.50 \%$ DBA except for Chol at $21 \mathrm{~d}$ and Chol and $\mathrm{HDL}$ at $42 \mathrm{~d}$, higher concentrations were reported in broilers fed $0.50 \%$ DBA. Previously, Hegsted et al. (1960) reported that the addition of cholic acid (an important component in the bile acid) to a diet containing $0.8 \%$ of cholesterol caused an increase in the serum cholesterol content of young chickens. Crespo \& Esteve-Garcia, (2003) also observed that the total cholesterol content of tallow-fed broilers was higher as compared to those fed sunflower and linseed oils. It has been shown that higher serum cholesterol content increased bile secretion and thus increased the digestion and absorption of fat 
(Eastwood \& Boyd, 1967). The low bile acid secretion can limit the digestion and absorption of fats particularly those enriching long chain saturated fatty acids (Ketels, 1994). The present results revealed that bile was higher in the small intestine; therefore, fat digestibility for $0.50 \%$ DBA was greater than that of the other treatments.

The effect of different levels of Tau and DBA on ileal digesta viscosity is given in Table 6. The supplementation of Tau and DBA to broiler diets and their interaction did not affect ileal digesta viscosity at 21 and 42 d. Similarly, Maisonnier et al. (2003) indicated that the addition of bile salts in the diets did not affect the small intestinal supernatant viscosity. Previously, it was shown that the supplementation of dissected ox bile to broiler diets did not affect ilea digesta viscosity (Alzawqari \& Nassiri, 2010).

Table 6 Effect of supplemental taurine (Tau) and dissected bile acid (DBA) levels on ileal digesta viscosity $\left(\mathrm{cPs}^{1}\right)$ of male broiler chickens at 21 and $42 \mathrm{~d}$ of age.

\begin{tabular}{lcc}
\hline Main effects & $21 \mathrm{~d}$ & Viscosity \\
\hline Tau (\%) & & $42 \mathrm{~d}$ \\
0.00 & 1.14 & \\
0.25 & 0.08 & 1.20 \\
0.50 & 1.07 & 1.18 \\
DBA (\%) & & 1.22 \\
0.00 & 1.12 & \\
0.25 & 1.10 & 1.22 \\
0.50 & 1.07 & 1.22 \\
SEM & 0.05 & 1.16 \\
Source of variance & & 0.07 \\
\hline Tau (\%) & & \\
BA (\%) & 0.193 & 0.809 \\
Tau $\times$ DBA & 0.515 & 0.605 \\
T'cps $=$ centipoises & 0.564 & 0.505 \\
& &
\end{tabular}

Table 7 shows the effect of different levels of Tau and DBA on carcass dressed weight, relative immune organs (percentage of live body weight) and small intestinal length $(\mathrm{cm})$ of male broiler chickens at $42 \mathrm{~d}$ of age. The supplementation of Tau or DBA in the diets did not affect carcass dressing, breast, thigh, abdominal fat percentages and small intestinal length of male broiler chickens at $42 \mathrm{~d}$ of age. However, small intestinal weight was reduced linearly as a result of DBA supplementation. Supplementation of the diets with Tau significantly increased bursa weights $(P<0.05)$. There were no significant differences in the spleen and liver weight among birds fed diet supplemented with different levels of Tau at $42 \mathrm{~d}$ of age. The supplementation of DBA to broiler diets did not affect bursa, spleen at $d 42$ of age while it decreased liver weight. Wang et al. (2014) reported that the relative weights of the bursa of Fabricius were higher when $0.05 \%$ Tau was added to the diet as compared with the control. A similar result was found in a study of Schuller-Levis et al. (1990), who reported that the relative weights of the thymus and bursa of Fabricius were increased due to dietary Tau and the absence of Tau could lead to a decrease in spleen weight. The bursa of Fabricius is a key lymphoid organ that is responsible for the development and maturation of Blymphocytes and Tau has a positive effect on immune responses (Li et al., 2007; Wang, 2001). The stimulatory effect of the Tau on growth and development of the lymphoid organ may be good at enhancing immune function. 
Table 7 Effect of supplemental taurine (Tau) and dissected bile acid (DBA) levels on the carcass characteristics (percentage of live body weight) at $42 \mathrm{~d}$ of age.

\begin{tabular}{|c|c|c|c|c|c|c|c|c|c|c|}
\hline \multicolumn{2}{|c|}{ Main effects } & $\begin{array}{c}\text { Carcass } \\
\text { dressing } \\
(\%)\end{array}$ & $\begin{array}{c}\text { Breast } \\
(\%)\end{array}$ & $\begin{array}{c}\text { Thigh } \\
(\%)\end{array}$ & $\begin{array}{l}\text { Fat } \\
(\%)\end{array}$ & $\begin{array}{c}\text { Small } \\
\text { intestine } \\
(\%)\end{array}$ & $\begin{array}{c}\text { Small } \\
\text { intestine } \\
(\mathrm{cm})\end{array}$ & $\begin{array}{c}\text { Bursa } \\
(\%)\end{array}$ & $\begin{array}{c}\text { Spleen } \\
(\%)\end{array}$ & $\begin{array}{c}\text { Liver } \\
(\%)\end{array}$ \\
\hline \multicolumn{11}{|c|}{ Tau (\%) } \\
\hline \multicolumn{2}{|c|}{0.00} & 58.3 & 22.0 & 19.6 & 1.6 & 5.1 & 151.6 & $0.12^{b}$ & 0.14 & 2.21 \\
\hline \multicolumn{2}{|c|}{0.25} & 58.3 & 20.8 & 18.9 & 1.9 & 4.8 & 150.7 & $0.15^{\mathrm{ab}}$ & 0.18 & 2.22 \\
\hline \multicolumn{2}{|c|}{0.50} & 58.4 & 21.8 & 19.3 & 1.9 & 4.8 & 143.3 & $0.19^{\mathrm{a}}$ & 0.16 & 2.23 \\
\hline \multicolumn{11}{|c|}{ DBA (\%) } \\
\hline \multicolumn{2}{|c|}{0.00} & 56.9 & 19.9 & 19.7 & 1.8 & $6.0^{\mathrm{a}}$ & 150.5 & 0.16 & 0.16 & $2.38^{\mathrm{a}}$ \\
\hline \multicolumn{2}{|c|}{0.25} & 60.0 & 22.9 & 19.3 & 1.8 & $4.4^{\mathrm{b}}$ & 148.3 & 0.16 & 0.17 & $2.15^{b}$ \\
\hline \multicolumn{2}{|c|}{0.50} & 58.0 & 21.8 & 19.0 & 1.8 & $4.3^{b}$ & 146.8 & 0.14 & 0.15 & $2.14^{b}$ \\
\hline \multicolumn{2}{|l|}{ SEM } & 0.78 & 0.87 & 0.42 & 0.11 & 0.13 & 2.88 & 0.07 & 0.01 & 0.06 \\
\hline \multicolumn{11}{|c|}{ Interaction effects } \\
\hline \multicolumn{2}{|r|}{ DBA } & & & & & & & & & \\
\hline \multicolumn{2}{|r|}{0.00} & 19.5 & 19.5 & 19.0 & $1.3^{\mathrm{b}}$ & 6.5 & 156.5 & 0.12 & 0.17 & 2.22 \\
\hline 0.00 & 0.25 & 25.0 & 25.0 & 19.6 & $1.7^{\mathrm{ab}}$ & 4.3 & 144.5 & 0.13 & 0.15 & 2.25 \\
\hline 0.00 & 0.50 & 21.6 & 21.6 & 20.2 & $1.9^{\mathrm{ab}}$ & 4.5 & 153.3 & 0.12 & 0.11 & 2.17 \\
\hline \multirow{2}{*}{$\begin{array}{l}0.25 \\
0.25\end{array}$} & 0.00 & 20.0 & 20.0 & 19.3 & $1.7^{\mathrm{ab}}$ & 5.9 & 154.8 & 0.16 & 0.17 & 2.35 \\
\hline & 0.25 & 20.4 & 20.4 & 18.5 & $2.1^{\mathrm{a}}$ & 4.5 & 147.0 & 0.19 & 0.21 & 2.15 \\
\hline 0.25 & 0.50 & 22.0 & 22.0 & 18.8 & $1.8^{\mathrm{ab}}$ & 4.0 & 150.3 & 0.09 & 0.18 & 2.17 \\
\hline \multirow{2}{*}{0.50} & 0.00 & 20.4 & 20.4 & 20.9 & $2.3^{\mathrm{a}}$ & 5.5 & 140.3 & 0.22 & 0.15 & 2.56 \\
\hline & 0.25 & 23.4 & 23.4 & 19.8 & $1.6^{\mathrm{ab}}$ & 4.5 & 153.3 & 0.17 & 0.16 & 2.06 \\
\hline & 0.50 & 21.7 & 21.7 & 17.4 & $1.7^{\mathrm{ab}}$ & 4.5 & 136.5 & 0.21 & 0.16 & 2.06 \\
\hline \multicolumn{2}{|c|}{ Source of variance } & \multicolumn{9}{|c|}{$P$-value } \\
\hline \multicolumn{2}{|c|}{ Tau (\%) } & 0.997 & 0.651 & 0.545 & 0.239 & 0.438 & 0.177 & 0.034 & 0.128 & 0.989 \\
\hline \multicolumn{2}{|c|}{ DBA (\%) } & 0.067 & 0.123 & 0.400 & 0.941 & 0.001 & 0.737 & 0.580 & 0.620 & 0.033 \\
\hline \multicolumn{2}{|c|}{ Tau $\times$ DBA } & 0.441 & 0.595 & 0.099 & 0.052 & 0.145 & 0.152 & 0.364 & 0.506 & 0.229 \\
\hline
\end{tabular}

${ }^{\mathrm{abc}}$ Means with different superscripts within the same column are significantly different $(P<0.05)$.

\section{Conclusion}

The supplementation of Tau to broiler diets did not affect performance for the experimental periods. DBA increased $\mathrm{FI}$ at 0.25 and $0.50 \%$ while BWG and FCR were a function of the DBA level in the diet and noticeable improvements were obtained when $0.50 \%$ was used. Carcass characteristics were not affected by Tau or DBA supplementation. DBA supplementation decreased small intestinal weight linearly while Tau supplementation increased bursa weight. Fat digestibility was significantly affected by Tau and DBA supplementation. Increased DBA and Tau levels in the diet increased fat digestibility linearly at $42 \mathrm{~d}$.

The results of this study indicated that Tau had limited impact on performance and the improvements in fat digestibility and blood parameters were not reflected on performance while the supplementation of DBA at $0.50 \%$ had the best improvements in performance and blood characteristics and this could be explained in part by the increased fat digestibility.

\section{Acknowledgments}

The author extends his appreciation to the Deanship of Scientific Research at King Saud University for funding this work through research project No RGP-267.

\section{Authors' contributions}

AMA and MHA were in charge for planning and conducting the growth trial. IBA, ANA and HHA were in charge of collecting samples and lab analysis. 


\section{Conflict of Interest Declaration}

Authors declare no conflict of interest.

\section{References}

Abudabos, AM., 2014. Effect of fat source, energy level and enzyme supplementation and their interactions on broiler performance. S. Afr. J Anim. Sci. 44 (3), 280-287.

Alzawqari, M., Kermanshahi, H. \& Nassiri Moghaddam, H., 2010. The effect of glycine and desiccated ox bile supplementation on performance, fat digestibility, blood chemistry and ileal digesta viscosity of broiler chickens. Glob. Vet. 5, 187-194.

Alzawqari, M., Moghaddam, HN., Kermanshahi, H. \& Raji, AR., 2011. The effect of desiccated ox bile supplementation on performance, fat digestibility, gut morphology and blood chemistry of broiler chickens fed tallow diets. J. Appl. Anim. Res. 39, 169-174.

Azman, M.A., Ibrahim, H. \& Birben, N., 2005. Effects of various dietary fat sources on performance and body fatty acid composition of broiler chickens. Turkish J. Vet. Anim. Sci, 29: 811-819.

Begley, M., Gahan, CG. \& Hill, C., 2005. The interaction between bacteria and bile. FEMS Microbiol. Rev. $29,625-651$.

Blair, R., Jacob, JP. \& Gardiner, EE., 1991. Lack of an effect of taurine supplementation on the incidence of sudden death syndrome in male broiler chicks. Poult. Sci. 70, 554-560.

Campbell, GL. \& Classen, HL., 1989. Effect of dietary taurine supplementation on sudden death syndrome in broiler chickens. Can. J. Anim. Sci. 69, 509-512.

Chesney, RW., Helms, RA., Christensen, M., Budreau, AM., Han, X. \& Sturman, JA., 1998. The role of taurine in infant nutrition. Adv. Exp. Med. Biol. 442, 463-476.

Coleman, R., Iqbal, S. Godfrey, PP \& Billington, D., 1979. Membranes and bile formation. Composition of several mammalian biles and their membrane-damaging properties. Biochem. J. 178, 201-208.

Crespo, N. \& Esteve-Garcia, E., 2003. Polyunsaturated fatty acids reduce insulin and very low density lipoprotein levels in broiler chickens. Poult. Sci. 82, 1134-1139.

Divakaran, S., 2006. Taurine: an amino acid rich in fish meal. Avances en Nutrición Acuícola. VIII Simposium Internacional de Nutrición Acuícola, 15-17.

Eastwood, MA. \& Boyd, GS., 1967. The distribution of bile salts along the small intestine of rats. Biochim. Biophys. Acta Lipids Lipid Metabol. 137, 393-396.

Ebrahimi, A., Qotbi, AAA., Seidavi, A. \& Bahar, B., 2014. The effects of dietary supplementation of Citrus sinensis peel extract on production and quality parameters of broiler chicken. J. Appl. Anim. Res. 42, 445-450.

Fenton, TW. \& Fenton, M., 1979. An improved procedure for the determination of chromic oxide in feed and feces. Can. J. Anim. Sci. 59, 631-634.

Gomez, MX. \& Polin, D., 1976. The use of bile salts to improve absorption of tallow in chicks, one to three weeks of age. Poult. Sci. 55, 2189-2195.

Haslewood, G., 1967. Bile Salt. Methuen, London.

Hayes, KC., 1976. A review on the biological function of taurine. Nutr. Rev. 34, 161-165.

Hegsted, DM., Gotsis, A. \& Stare, FJ., 1960. The influence of dietary fats on serum cholesterol levels in cholesterol-fed chicks. J. Nutr. 70, 119-126.

Horwitz, W. \& Latimer, GW., 2005. Official methods of analysis of AOAC International.4, 1-106.

Huang, C., Guo, Y. \& Yuan J., 2014a. Dietary taurine impairs intestinal growth and mucosal structure of broiler chickens by increasing toxic bile acid concentrations in the intestine. Poult. Sci. 93 (6), 14751483.

Huang, C.X., Wang, B. Min, Z. \& Yuan, J., 2014b. Dietary inclusion level and time effects of taurine on broiler performance, meat quality, oxidative status and muscle taurine content. Br. Poult. Sci. 55(5), 598604.

Irvin, JL., Merker, H., Anderson, CE. \& Johnston, CG., 1939. The comparison of desiccated and normal Hog gallbladder bile. J. Biol. Chem. 131, 439-445.

Ketels, E., 1994. The metabolizable energy values of fats in poultry diets. Ph.D. thesis. University of Gent, Belgium.

Kocsar, LT., Bertok, L. \& Varteresz, V., 1969. Effect of bile acids on the intestinal absorption of endotoxin in rats. J. Bacteriol. 100, 220-223.

Lázaro, R., Latorre, MA., Medel, P., Gracia, M. \& Mateos, GG., 2004. Feeding regimen and enzyme supplementation to rye-based diets for broilers. Poult. Sci. 83, 152-160. 
Maisonnier, S., Gomez, J., Bree, A., Berri, C., Baeza, E. \& Carre, B., 2003. Effects of microflora status, dietary bile salts and guar gum on lipid digestibility, intestinal bile salts, and histomorphology in broiler chickens. Poult. Sci. 82, 805-814.

Matsushima, Y., Sekine, T., Kondo, Y., Sakurai, T., Kameo, K., Tachibana, M. \& Murakami, S., 2003. Effects of taurine on serum cholesterol levels and development of atherosclerosis in spontaneously hyperlipidaemic mice. Clin. Exp. Pharmacol. Physiol.30, 295-299.

Militante, JD. \& Lombardini, JB., 2004. Dietary taurine supplementation: hypolipidemic and antiatherogenic effects. Nutr. Res. 24, 787-801.

Noy, Y. \& Sklan, D., 2001. Yolk and exogenous feed utilization in the posthatch chick. Poult. Sci. 80, 14901495.

NRC. 1994. Nutrient Requirements of Poultry. 9th. ed. Natl. Acad. Press, Washington, DC.

Ohtani, S. \& Yayota, M., 2002. Dietary energy source and supplements in broiler diets containing defatted rice bran. J. Appl. Poult. Res. 11, 410-417.

Parsaie, S., Shariatmadari, F., Zamiri, MJ. \& Khajeh, K., 2007. Influence of wheat-based diets supplemented with xylanase, bile acid and antibiotics on performance, digestive tract measurements and gut morphology of broilers compared with a maize-based diet. Br. Poult. Sci. 48, 594-600.

Preston, CM., McCracken, KJ., \& Bedford, MR., 2001. Effect of wheat content, fat source and enzyme supplementation on diet metabolisability and broiler performance. Br. Poult. Sci. 42, 625-632.

Reshetnyak, VI., 2013. Physiological and molecular biochemical mechanisms of bile formation. WJG. 19, 7341-7360.

SAS., 2004. Statistical Analysis Systems user's guide (9.1 ed.). SAS Institute Inc., Raleigh, North Carolina, USA.

Schuller-Levis, G., Mehta, PD., Rudelli, R. \& Sturman, J., 1990. Immunologic consequences of taurine deficiency in cats. J. Leukoc. Biol. 47, 321-331.

Scott, ML., Nesheim, MC. \& Young, RJ., 1976. Nutrition of the chicken. Nutrition of the chicken. Edition M. L. Scott \& Associates, Ithaca new york.7-54.

Shim, KS., Park, GH., Na, CS., Ji, JR. \& Choe, HS., 2010. Effects of taurine supplementation on performance, egg quality, blood parameter and liver lipid and lipid peroxidation levels of laying hens fed high fat diet. Korean. J. Poult. Sci. 37, 337-345.

Steel, RG. \& Torrie, JH., 1980. Analysis of covariance. Principles and procedures of statistics: A Biometrical Approach, 401-437.

Tufft, LS. \& Jensen, LS., 1992. Influence of dietary taurine on performance and fat retention in broilers and turkey poults fed varying levels of fat. Poult. Sci. 71, 880-885.

Wang, FR., Dong, XF., Tong, JM., Zhang, XM., Zhang, Q. \& Wu, YY., 2009. Effects of dietary taurine supplementation on growth performance and immune status in growing Japanese quail (Coturnix coturnix japonica). Fish. Sci. 88, 1394-1398.

Wang, Q., He, G., Wang, X., Mai, K., Xu, W. \& Zhou, H., 2014. Dietary sulfur amino acid modulations of taurine biosynthesis in juvenile turbot (Psetta maxima). Aquaculture, 422, 141-145.

Young, RJ., Garrett, R. L. \& Griffith, M., 1963. Factors affecting the absorbability of fatty acid mixtures high in saturated fatty acids. Poult. Sci, 42, 1146-1154.

Zeng, DS., Gao, ZH., Huang, XL., Zhao, JH., Huang, GQ. \& Duo, L., 2012. Effect of taurine on lipid metabolism of broilers. J Appl. Anim. Res. 40, 86-89. 